\title{
The Effect of Preoperative Oral Antibiotics in the Prevention of Surgical Site Infection after Laparoscopic Colorectal Cancer Surgery: A Propensity Score Matching Study
}

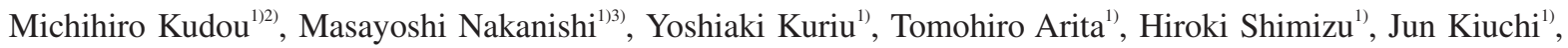 \\ Keita Katsurahara $^{1)}$, Hisashi Ikoma ${ }^{1)}$, Takeshi Kubota ${ }^{1)}$, Hitoshi Fujiwara ${ }^{1)}$, Kazuma Okamoto ${ }^{1)}$ and Eigo Otsuji1) \\ 1) Division of Digestive Surgery, Department of Surgery, Kyoto Prefectural University of Medicine, Kyoto, Japan \\ 2) Department of Surgery, Kyoto Okamoto Memorial Hospital, Kyoto, Japan \\ 3) Department of Surgery, Matsushita Memorial Hospital, Osaka, Japan
}

\begin{abstract}
Objectives: Recent findings suggest that the combination of mechanical bowel preparation (MBP) and preoperative oral antibiotics (OA) decreases the risk of surgical site infection (SSI) in colorectal surgery; however, this remains controversial. The present study examined the efficacy of OA plus MBP in laparoscopic colorectal cancer (CRC) surgery using propensity score matching (PSM).

Methods: A total of 1080 patients with CRC underwent MBP followed by laparoscopic surgery between 2007 and 2019. OA was administered to all patients with CRC who underwent colectomy from 2018. PSM was performed to compare the effects of OA plus MBP (OA) versus MBP only (non-OA) on the rate of superficial SSI.

Results: Overall, 128 patients received OA. Significant differences were observed in age, the American Society of Anesthesiologists performance status (ASA-PS), liver disease, and preoperative serum albumin (Alb) between the OA and non-OA groups. The enrolled patients were matched using PSM into two groups based on the following factors: sex, age, body mass index, ASA-PS, diabetes mellitus, liver disease, Alb, and tumor location, which resulted in the disappearance of significant differences. A univariate analysis showed that blood loss of $100 \mathrm{~g}$ or more, non-OA, and preoperative chemotherapy or radiation correlated with SSI $(p=0.021,0.010,0.038)$. A multivariate analysis of these three variables identified blood loss of $100 \mathrm{~g}$ or more and non-OA as independent risk factors for SSI (hazard ratio (HR): $3.238, p=0.031$; HR: 2.547, $p=0.033$ ).

Conclusions: The present study revealed that OA plus MBP markedly reduced SSI rate. OA with MBP needs to be adopted in laparoscopic CRC surgery.

\section{Keywords}

oral antibiotics, surgical site infection, colorectal cancer, laparoscopic surgery, propensity score matching
\end{abstract}

J Anus Rectum Colon 2021; 5(3): 319-326

\section{Introduction}

Surgical wounds in colorectal cancer (CRC) surgery have been categorized as clean-contaminated wounds (Class II) based on the surgical wound calcification grade defined by the Centers for Disease Control and Prevention (CDC)[1]. Surgical site infection (SSI) rate is higher in clearcontaminated surgery, such as CRC surgery, than in other 
clean surgeries[2,3]. The high rate of SSI in CRC surgery has a negative impact on short-term outcomes, lengthens hospital stays, increases medical costs, and worsens esthetic outcomes[4,5]. A relationship was recently reported between postoperative infectious complications and long-term outcomes in CRC, with SSI or anastomotic leakage decreasing the overall and relapse-free survival in patients with CRC[6-8]. These outcomes were suggested and proven in basic and clinical research. Furthermore, systematic or focal inflammation was shown to induce tumor proliferation, invasion, or metastasis[9,10]. In clinical research, high values for perioperative serum inflammation markers were found to be associated with survival in patients with CRC[11,12]. Therefore, the prevention of SSI may contribute not only to better short-term outcomes after surgery but also to long-term oncological outcomes in CRC, and various strategies have been adopted to reduce SSI rate.

The clinical importance of intravenous antibiotics in the perioperative setting to prevent SSI has already been confirmed[13-15]. Mechanical bowel preparation (MBP) has mainly been employed; however, it is not preferred in Europe because MBP alone does not affect SSI rate[16], and enhanced recovery after surgery (ERAS) protocols also avoid it[17]. Controversy remains regarding oral antibiotics $(\mathrm{OA})$ in the preoperative setting. Although the use of OA has been recommended by the CDC, they are not administered in Japan because preoperative OA may increase the risk of methicillin-resistant Staphylococcus aureus infection. However, recent studies reported that short-term OA did not promote an outbreak of resistant bacteria[18], and the combination of MBP and preoperative OA decreased the rate of SSI[19,20]. Based on these findings, preoperative OA plus MBP has been recommended for use in Japan since 2019[21].

These recommendations were based on a mixture of data obtained from open, laparoscopic, elective, and nonelective surgery. Since the rate of laparoscopic surgery in CRC surgery has markedly increased in the past decade, the risk of postoperative complications also needs to be evaluated in a cohort including only laparoscopic surgery.

Meanwhile, the diversity of patient background also exists in laparoscopic surgery. The length of surgical incision in laparoscopic surgery of the right side colon is generally longer than that in the left side colon, which may be associated with SSI rate. Moreover, multimodal therapies containing preoperative chemotherapies or chemoradiotherapies have been widely performed for patients with CRC in recent years. Preoperative therapies may affect the rate of SSI. Therefore, we considered that the effect of OA in the prevention of SSI should be analyzed in laparoscopic colectomy under the homogenization of the diversity using propensity score matching (PSM) to exactly evaluate the significance of OA. Many retrospective and prospective studies have examined the clinical value of OA; however, few cohort studies using PSM have been conducted to date[22,23]. The present study investigated the clinical value of $\mathrm{OA}$ in laparoscopic CRC surgery using PSM.

\section{Patients and Methods}

All methods were conducted in accordance with relevant guidelines[24].

\section{Study design and patients}

This was a retrospective diagnostic accuracy study that used PSM to investigate the clinical value of OA combined with MBP in laparoscopic CRC surgery. The present study included patients with CRC who underwent curative surgery between April 2007 and December 2019 at the Division of Digestive Surgery of Kyoto Prefectural University of Medicine (KPUM). The exclusion criteria were as follows: (1) patients with bowel obstruction caused by a tumor, (2) patients with colon cancer that prevented the passage of endoscope into the proximal side of the tumor, (3) patients who did not receive preoperative MBP, and (4) patients who underwent open surgery or conversion from laparoscopic to open surgery.

\section{Ethical approval and consent to participate}

The present study was approved by the Research Ethics Committee of the Kyoto Prefectural University of Medicine (No. ERB-C-1187-1). Comprehensive informed consent for the use of clinical data was obtained from all eligible patients. Moreover, informed consent was also obtained from the parents and/or legal guardians of minor patients involved in the study (age under 18 years).

\section{$M B P$ and preoperative $O A$}

MBP, consisting of magnesium citrate $34 \mathrm{~g}$ and sodium pyrosulfate $75 \mathrm{mg}$, was performed on the day prior to surgery. A glycerin enema was also conducted on the morning of surgery. Preoperative OA were administered to all patients with CRC who underwent colectomy in KPUM from January 2018. In patients who underwent preoperative OA, kanamycin $2 \mathrm{~g} / \mathrm{day}$ and metronidazole $2 \mathrm{~g}$ /day were perorally administered in two doses after MBP on the day prior to surgery.

\section{Other preventative strategies for SSI}

Cefmetazole sodium was intravenously administered during surgery and on postoperative days 1 and 2. All gloves were changed after operations, such as bowel anastomosis or intestinal transection. Wound lavage was performed after fascia closure using $500 \mathrm{ml}$ saline. The skin and fascia were sutured using absorbable monocryl. The preventative method of SSI besides OA was performed for all eligible patients in 


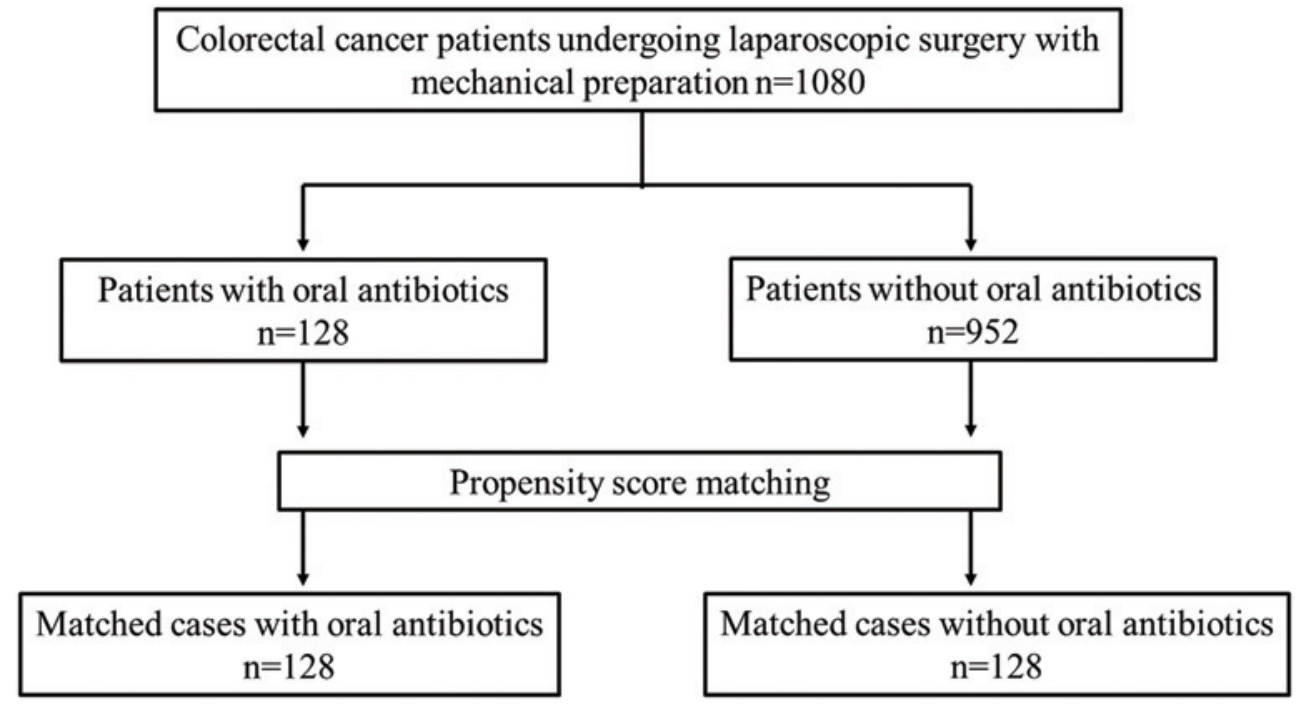

Figure 1. Flowchart showing the selection process for patient inclusion in the present study.

the same way.

\section{Definition of SSI}

SSI were diagnosed by surgeons or the colorectal cancer team of KPUM according to the CDC definition[1]. In the present study, incisional SSI rate was analyzed. The occurrence of SSI was recorded into the CRC database of KPUM until the discharge of patients. SSI data in the present study was extracted from the database.

\section{Surgical procedures}

All surgeries were performed or supervised by surgeons with sufficient experience and certificated by the Japan Society of Endoscopic Surgery and the Japanese Society of Gastrointestinal Surgery. The surgical procedure was selected based on the Japanese CRC guidelines[25]. Colectomy with radical lymph node dissection was performed on all patients with CRC.

\section{Statistical analysis}

A univariate analysis was performed using the variables of patients with CRC, grouped by OA (OA and non-OA groups). The Student's $t$-test was used for parametric continuous variables and the Mann-Whitney test for nonparametric variables. For categorical variables, the chi-squared test or Fisher's exact test was used. A multivariate analysis was performed using a logistic regression analysis to investigate the relationship between preoperative OA and SSI rate.

PSM was used to perform a 1:1 match on the following eight factors in two groups: sex, age, body mass index (BMI), the American Society of Anesthesiologists performance status (ASA-PS), diabetes mellitus, liver disease, preoperative serum albumin (Alb) levels, tumor location, and preoperative therapies. The match tolerance of PSM was set at 0.20 , and replacements were not allowed. All statistical tests were two-sided. $\mathrm{P}$ values of less than 0.05 were considered to be significant. All statistical analyses were performed using JMP version 10.

\section{Results}

\section{Clinicopathological characteristics of all enrolled cases}

The present study targeted 1080 patients with CRC according to inclusion and exclusion criteria, and 128 received preoperative OA. A flowchart of the present study is shown in Figure 1. Patient characteristics are summarized in Table 1. The median of age of patients was 67 years (14-93 years). The median BMI was $22.2 \mathrm{~kg} / \mathrm{m}^{2}(12.2-40.0)$. There were 126 and 17 patients with diabetes mellitus and severe liver disease, respectively. The median preoperative serum Alb value was $4.2 \mathrm{mg} / \mathrm{dl}(1.3-5.3 \mathrm{mg} / \mathrm{dl})$. The tumor location was on the left side (rectum, sigmoid, and descending colon) in 723 patients and on the right side in 357 patients. Overall, 43 patients received preoperative chemotherapy or chemoradiotherapy. The median surgical time and blood loss were 219 minutes and $10 \mathrm{~g}$, respectively. Incision SSI occurred in 121 patients $(11.2 \%)$ and anastomotic leakage in $36(3.3 \%)$.

\section{Relationship between $O A$ and clinical factors before PSM}

The relationships between $\mathrm{OA}$ and clinical factors in all patients were examined (Table 2). No significant differences were observed in sex, BMI, diabetes mellitus, or tumor location. The OA group was significantly older than the non-OA group ( $p=0.038$ ). Preoperative serum Alb levels were significantly lower in the OA group than in the non-OA group $(p<0.001)$. The physical status of the OA group was sig- 
Table 1. Patient Characteristics before Propensity Matching.

\begin{tabular}{|c|c|c|c|}
\hline & & $\mathrm{n}$ & \\
\hline Total cases & & 1080 & \\
\hline \multicolumn{4}{|l|}{ Clinical characteristics } \\
\hline \multirow[t]{2}{*}{ Gender } & Male & 604 & \\
\hline & Female & 476 & \\
\hline Age & Median & 67 & $(14-93)$ \\
\hline Body mass index & Median & 22.2 & $(12.2-40)$ \\
\hline \multirow[t]{4}{*}{ ASA } & 1 & 657 & \\
\hline & 2 & 387 & \\
\hline & 3 & 35 & \\
\hline & 4 & 1 & \\
\hline \multirow[t]{2}{*}{ Diabetes mellitus } & $(+)$ & 126 & \\
\hline & $(-)$ & 954 & \\
\hline \multirow[t]{2}{*}{ Liver disease } & $(+)$ & 17 & \\
\hline & $(-)$ & 1063 & \\
\hline Serum albumin (mg/dl) & Median & 4.2 & $(1.3-5.3)$ \\
\hline \multirow[t]{2}{*}{ Location } & Left & 723 & \\
\hline & Right & 357 & \\
\hline \multirow[t]{2}{*}{ Oral antibiotics } & $(+)$ & 128 & \\
\hline & $(-)$ & 952 & \\
\hline \multirow[t]{2}{*}{ Preoperative therapy } & $(+)$ & 43 & \\
\hline & $(-)$ & 1037 & \\
\hline \multicolumn{4}{|l|}{ Surgical findings } \\
\hline Surgical time & & 219 & $(70-1009)$ \\
\hline Blood loss & Median & 10 & $(10-1843)$ \\
\hline \multicolumn{4}{|l|}{ Postoperative complications } \\
\hline \multirow[t]{2}{*}{ Surgical site infection } & $(+)$ & 121 & \\
\hline & $(-)$ & 959 & \\
\hline \multirow[t]{2}{*}{ Anastomotic leakage } & $(+)$ & 36 & \\
\hline & $(-)$ & 1044 & \\
\hline
\end{tabular}

ASA-PS, American Society of Anesthesiologists performance status; left, left-side colon (rectum, sigmoid, and descending colon); right, right-side colon (transverse, ascending colon and cecum)

nificantly worse than that of the non-OA group $(p<0.001)$. The number of patients with severe liver disease was significantly higher in the OA group than in the non-OA group ( $p$ $=0.002$ ).

\section{PSM between $\mathrm{OA}$ and non-OA groups}

PSM between the OA and non-OA groups was performed on the eight factors shown in Table 2. The relationship between OA and clinical factors in matched cases was shown in Table 3. No significant differences were observed in any of the factors tested between the OA and non-OA groups ( $p$ $=0.283-1.000$ ).

\section{Clinical value of preoperative OA for preventing SSI}

Univariate and multivariate analyses of the relationships between SSI and clinical factors are shown in Table 4. No significant differences were observed in sex, age, BMI, ASA-PS, diabetes mellitus, liver disease, serum Alb levels, tumor location, or SSI. Blood loss, preoperative therapy, and
OA correlated with the rate of SSI $(p=0.021,0.010$, and 0.038 , respectively). The multivariate analysis of significant factors identified blood loss of $100 \mathrm{~g}$ or more and oral non$\mathrm{OA}$ as independent risk factors for predicting SSI (hazard ratio (HR): 3.238 , 95\% confidence interval (CI): 1.1198.712, $p=0.031$; and HR: 2.547, 95\%CI: 1.072-6.590, $p=$ 0.033 , respectively).

\section{Discussion}

Over the past 20 years, advances have been achieved in surgical techniques for CRC. Open colectomy was the standard surgery as a curative treatment until the 1980s and involved a long surgical incision of between 20 and $30 \mathrm{~cm}$. Jacobs et al. performed the first series of laparoscopic colonic resections on 20 patients in 1991[26], and evidence for the safety and efficacy of laparoscopic colectomy was established[27-29]. The rate of laparoscopic surgery in all CRC surgeries was $72.0 \%$ in Japan in 2015. In our institute, the rate of laparoscopic surgery and conversion rate from laparoscopic to open surgery in 2018 were $91.6 \%$ and $3.3 \%$, respectively. Since laparoscopic surgery is less invasive than open surgery, the rate of postoperative complications was predicted to be lower. Based on the background of CRC surgery, a cohort that contains only patients undergoing laparoscopic or open surgery needs to be analyzed in clinical research aimed at investigating the risk of postoperative complications in these surgeries.

Therefore, we herein examined the clinical value of $\mathrm{OA}$ using a cohort of patients with CRC undergoing laparoscopic surgery. The clinical value of OA was initially analyzed without PSM, and the results obtained showed that the right side colon, operative time, and BMI were independent risk factors of SSI (Supplement Table 1). The surgical procedure of laparoscopic surgery for the right side colon in our institute is as follows: (1) the right side of the colon is mobilized, (2) the artery and vein are dissected, and (3) the mobilized right side and ileum are pulled outside the abdomen. Therefore, the surgical incision for removing resected specimens needs to be sufficiently long to allow the passage of two intestinal tracts. However, the subcutaneous fat of patients with a high BMI or females under the surgical incision was thicker than that of patients with a low BMI or males, suggesting that the rate of SSI may be higher in these patients. Based on the results shown in Supplement Table 1, the homogenization of the frequency of these variables between the OA and non-OA groups needs to be performed using a statistical matching method, such as PSM, to accurately analyze the efficacy of OA.

The present study demonstrated that OA, blood loss, and preoperative therapies correlated with the rate of SSI in the univariate analysis. The multivariate analysis showed that blood loss and OA were independent risk factors for predict- 
Table 2. The Association of OA with Clinical Factors before Propensity Matching.

\begin{tabular}{|c|c|c|c|c|c|c|}
\hline \multirow{2}{*}{ Variables } & & \multicolumn{2}{|c|}{ Oral antibiotics $(+)$} & \multicolumn{2}{|c|}{ Oral antibiotics (-) } & \multirow{2}{*}{$p$} \\
\hline & & $\mathrm{n}=128$ & $\%$ & $\mathrm{n}=952$ & $\%$ & \\
\hline \multirow[t]{2}{*}{ Gender } & Male & 73 & 57 & 531 & 55.8 & 0.788 \\
\hline & Female & 55 & 43 & 421 & 44.2 & \\
\hline Age & Mean + SD & $68.3 \pm 12.4$ & & $65.8 \pm 11.6$ & & 0.038 \\
\hline Body mass index & & $22.6 \pm 3.5$ & & $22.5 \pm 3.4$ & & 0.607 \\
\hline \multirow[t]{4}{*}{ ASA-PS } & 1 & 53 & 41.4 & 604 & 63.4 & $<0.001$ \\
\hline & 2 & 68 & 53.1 & 319 & 33.5 & \\
\hline & 3 & 7 & 5.5 & 28 & 2.9 & \\
\hline & 4 & 0 & 0 & 1 & 0.1 & \\
\hline \multirow[t]{2}{*}{ Diabetes mellitus } & $(+)$ & 19 & 14.8 & 107 & 11.2 & 0.233 \\
\hline & $(-)$ & 109 & 85.2 & 845 & 88.8 & \\
\hline \multirow[t]{2}{*}{ Liver disease } & $(+)$ & 6 & 4.7 & 11 & 1.2 & 0.002 \\
\hline & $(-)$ & 122 & 95.3 & 941 & 98.8 & \\
\hline Albumin (mg/dl) & Mean + SD & $3.98 \pm 0.5$ & & $4.18 \pm 0.4$ & & $<0.001$ \\
\hline \multirow[t]{2}{*}{ Location } & Right & 45 & 35.2 & 312 & 32.8 & 0.590 \\
\hline & Left & 83 & 64.8 & 640 & 67.2 & \\
\hline \multirow[t]{2}{*}{ Preoperative therapies } & $(+)$ & 9 & 7 & 34 & 3.5 & 0.060 \\
\hline & $(-)$ & 119 & 92.9 & 918 & 96.4 & \\
\hline
\end{tabular}

SD, standard deviation; ASA-PS, American Society of Anesthesiologists performance status; left, left-side colon (rectum, sigmoid, and descending colon); right, right-side colon (transverse, ascending colon and cecum)

Table 3. The Association of OA with Clinical Factors after Propensity Matching.

\begin{tabular}{|c|c|c|c|c|c|c|}
\hline \multirow{2}{*}{ Variables } & & \multicolumn{2}{|c|}{ Oral antibiotics $(+)$} & \multicolumn{2}{|c|}{ Oral antibiotics (-) } & \multirow{2}{*}{$p$} \\
\hline & & 128 & $\%$ & 128 & $\%$ & \\
\hline \multirow[t]{2}{*}{ Gender } & Male & 73 & 57 & 76 & 59.4 & 0.703 \\
\hline & Female & 55 & 43 & 52 & 40.6 & \\
\hline Age & Mean + SD & $68.3 \pm 12.4$ & & $67.6 \pm 11$ & & 0.683 \\
\hline Body mass index & & $22.6 \pm 3.5$ & & $22.6 \pm 3.6$ & & 0.976 \\
\hline \multirow[t]{3}{*}{ ASA-PS } & 1 & 53 & 41.4 & 53 & 41.4 & 1.000 \\
\hline & 2 & 68 & 53.1 & 68 & 53.1 & \\
\hline & 3 & 7 & 5.5 & 7 & 5.5 & \\
\hline \multirow[t]{2}{*}{ Diabetes mellitus } & $(+)$ & 19 & 14.8 & 14 & 10.9 & 0.351 \\
\hline & $(-)$ & 109 & 85.2 & 114 & 89.1 & \\
\hline \multirow[t]{2}{*}{ Liver disease } & & 6 & 4.7 & 7 & 5.5 & 0.775 \\
\hline & & 122 & 95.3 & 121 & 94.5 & \\
\hline Albumin (mg/dl) & & $3.98 \pm 0.5$ & & $3.98 \pm 0.61$ & & 0.991 \\
\hline \multirow[t]{2}{*}{ Location } & Right & 45 & 35.2 & 37 & 28.9 & 0.283 \\
\hline & Left & 83 & 64.8 & 91 & 71.1 & \\
\hline \multirow[t]{2}{*}{ Preoperative therapies } & $(+)$ & 9 & 7 & 9 & 7 & 1.000 \\
\hline & $(-)$ & 119 & 92.9 & 119 & 92.9 & \\
\hline
\end{tabular}

SD, standard deviation; ASA-PS, American Society of Anesthesiologists performance status; left, left-side colon (rectum, sigmoid, and descending colon); right, right-side colon (transverse, ascending colon and cecum)

ing SSI. Although a significant difference was not detected in BMI, SSI rate was slightly higher in patients with a high BMI than in those with a low BMI $(7.7 \%$ vs $2.2 \%, p<$ 0.102). In future studies using a large cohort, BMI may also correlate with SSI. Furthermore, the rate of postoperative complications did not increase after OA administration, and hospital stays were slightly shorter in the OA group than in the non-OA group (data was not shown). These results suggest that preoperative OA with MBP is safe and effective for the prevention of SSI in laparoscopic surgery for patients 
Table 4. Univariate and Multivariate Analyses for Detecting Risk Factors of Surgical Site Infection.

\begin{tabular}{|c|c|c|c|c|c|c|c|c|c|}
\hline & & \multicolumn{5}{|c|}{ Univariate analysis } & \multicolumn{3}{|c|}{ Multivariate analysis } \\
\hline & & $\begin{array}{c}\text { SSI (+) } \\
\mathrm{n}=26\end{array}$ & & $\begin{array}{l}\text { SSI (-) } \\
\mathrm{n}=230\end{array}$ & & $p$ & HR & $95 \%$ CI & $p$ \\
\hline \multirow[t]{2}{*}{ Gender } & Male & 17 & 65.4 & 132 & 57.4 & 0.433 & & & \\
\hline & Female & 9 & 34.6 & 98 & 42.6 & & & & \\
\hline \multirow[t]{2}{*}{ Age } & $\geq 81$ & 1 & 3.8 & 31 & 13.5 & 0.159 & & & \\
\hline & $<81$ & 25 & 96.2 & 199 & 86.5 & & & & \\
\hline \multirow[t]{2}{*}{ Body mass index } & $\geq 30$ & 2 & 7.7 & 5 & 2.2 & 0.102 & & & \\
\hline & $<30$ & 24 & 92.3 & 225 & 97.8 & & & & \\
\hline \multirow[t]{3}{*}{ ASA-PS } & 1 & 10 & 38.5 & 96 & 41.7 & 0.850 & & & \\
\hline & 2 & 14 & 53.8 & 122 & 53 & & & & \\
\hline & 3 & 2 & 7.7 & 12 & 5.2 & & & & \\
\hline \multirow{2}{*}{ Diabetes mellitus } & $(+)$ & 4 & 15.4 & 29 & 12.6 & 0.689 & & & \\
\hline & $(-)$ & 22 & 84.6 & 201 & 87.4 & & & & \\
\hline \multirow[t]{2}{*}{ Liver disease } & $(+)$ & 1 & 3.8 & 12 & 5.2 & 0.762 & & & \\
\hline & $(-)$ & 25 & 96.2 & 218 & 94.8 & & & & \\
\hline \multirow{2}{*}{ Severe renal disease } & $(+)$ & 1 & 3.8 & 3 & 1.3 & 0.321 & & & \\
\hline & $(-)$ & 25 & 96.1 & 227 & 98.7 & & & & \\
\hline \multirow[t]{2}{*}{ Severe pulmonary disease } & $(+)$ & 0 & 0 & 4 & 1.7 & 0.497 & & & \\
\hline & $(-)$ & 26 & 100 & 226 & 98.2 & & & & \\
\hline \multirow{2}{*}{ Steroid use } & $(+)$ & 0 & 0 & 5 & 2.1 & 0.447 & & & \\
\hline & $(-)$ & 26 & 100 & 225 & 97.8 & & & & \\
\hline \multirow[t]{2}{*}{ Albumin (mg/dl) } & $\geq 3$ & 25 & 96.2 & 215 & 93.5 & 0.593 & & & \\
\hline & $<3$ & 1 & 3.8 & 15 & 6.5 & & & & \\
\hline \multirow{2}{*}{ Hemoglobin (g/dl) } & $\geq 10$ & 20 & 76.9 & 150 & 65.2 & 0.231 & & & \\
\hline & $<10$ & 6 & 23 & 80 & 34.7 & & & & \\
\hline \multirow[t]{2}{*}{ Location } & Right & 9 & 34.6 & 73 & 31.7 & 0.767 & & & \\
\hline & Left & 17 & 65.3 & 157 & 68.2 & & & & \\
\hline \multirow[t]{2}{*}{ Surgical time } & $\geq 210$ & 16 & 61.5 & 125 & 54.3 & 0.484 & & & \\
\hline & $<210$ & 10 & 38.5 & 105 & 45.7 & & & & \\
\hline \multirow[t]{2}{*}{ Blood loss } & $\geq 100$ & 8 & 30.8 & 23 & 10 & 0.021 & 3.238 & $1.119-8.712$ & 0.031 \\
\hline & $<100$ & 18 & 69.2 & 207 & 90 & & Ref & & \\
\hline \multirow{2}{*}{ Oral antibiotics } & $(-)$ & 18 & 69.2 & 110 & 47.8 & 0.038 & 2.547 & $1.072-6.590$ & 0.033 \\
\hline & $(+)$ & 8 & 30.8 & 120 & 52.2 & & Ref & & \\
\hline \multirow[t]{2}{*}{ Preoperative therapy } & $(+)$ & 5 & 19.2 & 13 & 5.7 & 0.010 & 2.717 & $0.724-8.930$ & 0.131 \\
\hline & $(-)$ & 21 & 80.8 & 217 & 94.3 & & Ref & & \\
\hline
\end{tabular}

ASA-PS, American Society of Anesthesiologists performance status; severe renal disease, severe chronic renal disease or dialysis patients; severe pulmonary disease, respiratory failure with oxygen administration; steroid use, $5 \mathrm{mg}$ or more prednisolone per day.

with CRC.

The present study has some limitations. This was a retrospective study with a small sample size, which may have limited the statistical power and generated a statistical bias. Although PSM was used to limit selection bias, some residual confounding factors may still have been unaccounted for. The longitudinal nature of the present study may have introduced a statistical bias between two groups due to changes in anesthetic or surgical techniques over the time period included; however, no major changes were noted other than the administration of OA.

\section{Conclusion}

The present PSM study using a cohort of patients who underwent laparoscopic CRC surgery only revealed that OA plus MBP prevented the occurrence of SSI, which is consistent with previous findings. OA with MBP needs to be adopted in laparoscopic surgery for colon cancer cases.

Conflicts of Interest

There are no conflicts of interest.

Author Contributions

M.K. and M.N. analyzed and interpreted the patient data 
and were the major contributor in writing the manuscript. Y. K., T.A., H.S, J.K., H.I., T.K., H.F., and K.O. collected the patient data, such as clinicopathological factors. E.O. supervised all of the present study. K.K. performed a propensity score matching of the cohort. All of authors read and approved the final manuscript.

\section{Approval by Institutional Review Board (IRB)}

The present study was approved by the Research Ethics Committee of the Kyoto Prefectural University of Medicine (No. ERB-C-1187-1). Comprehensive informed consent for the use of clinical data was obtained from all eligible patients. Moreover, informed consent was also obtained from the parents and/or legal guardians of minor patients involved in the study (age under 18 years).

\section{References}

1. Surgical Site Infection (SSI) Protocols: Center for Disease Control. 2021[Internet]. 2021 Jan [cited 2007 Jan 1]. Available from: https://www.cdc.gov/nhsn/opc/ssi/index.html

2. Winfield RD, Reese S, Bochicchio K, et al. Obesity and the risk for surgical site infection in abdominal surgery. The American surgeon. 2016 Apr;82(4):331-6. eng. Epub 2016/04/22. Cited in: Pubmed; PMID 27097626.

3. Carvalho RLR, Campos CC, Franco LMC, et al. Incidence and risk factors for surgical site infection in general surgeries. Rev Lat Am Enfermagem. 2017 Dec 4;25:e2848. doi:10.1590/15188345.1502.2848. Cited in: Pubmed; PMID 29211190.

4. Badia JM, Casey AL, Petrosillo N, et al. Impact of surgical site infection on healthcare costs and patient outcomes: a systematic review in six European countries. J Hosp Infect. 2017 May;96(1): 1-15. doi:10.1016/j.jhin.2017.03.004. Cited in: Pubmed; PMID 28410761.

5. Keenan JE, Speicher PJ, Thacker JK, et al. The preventive surgical site infection bundle in colorectal surgery: an effective approach to surgical site infection reduction and health care cost savings. JAMA surgery. 2014 Oct;149(10):1045-52. eng. Epub 2014/08/28. doi:10.1001/jamasurg.2014.346. Cited in: Pubmed; PMID 25163027.

6. Artinyan A, Orcutt ST, Anaya DA, et al. Infectious postoperative complications decrease long-term survival in patients undergoing curative surgery for colorectal cancer: a study of 12,075 patients. Ann Surg. 2015 Mar;261 (3) : 497-505. doi : 10.1097/ SLA.0000000000000854. Cited in: Pubmed; PMID 25185465.

7. Aoyama T, Oba K, Honda M, et al. Impact of postoperative complications on the colorectal cancer survival and recurrence: analyses of pooled individual patients' data from three large phase III randomized trials. Cancer Med. 2017 Jul;6(7):1573-80. doi: 10.1002/cam4.1126. Cited in: Pubmed; PMID 28639738.

8. Salvans S, Mayol X, Alonso S, et al. Postoperative peritoneal infection enhances migration and invasion capacities of tumor cells in vitro: an insight into the association between anastomotic leak and recurrence after surgery for colorectal cancer. Ann Surg. 2014 Nov; 260 ( 5 ) : 939-43; discussion 943-4. doi : 10.1097 / SLA.0000000000000958. Cited in: Pubmed; PMID 25243554.

9. Candido J, Hagemann T. Cancer-related inflammation. J Clin Immunol. 2013 Jan;33 Suppl 1:S79-84. doi:10.1007/s10875-012-
9847-0. Cited in: Pubmed; PMID 23225204.

10. Tuomisto AE, Makinen MJ, Vayrynen JP. Systemic inflammation in colorectal cancer: Underlying factors, effects, and prognostic significance. World J Gastroenterol. 2019 Aug 21;25(31):4383404. doi:10.3748/wjg.v25.i31.4383. Cited in: Pubmed; PMID 31496619.

11. Matsubara D, Arita T, Nakanishi M, et al. The impact of postoperative inflammation on recurrence in patients with colorectal cancer. Int J Clin Oncol. 2019 Nov 22. doi:10.1007/s10147-01901580-1. Cited in: Pubmed; PMID 31758273.

12. Matsubara D, Arita T, Nakanishi M, et al. Preoperative inflammatory response as prognostic factor of patients with colon cancer. Langenbecks Arch Surg. 2019 Sep;404(6):731-41. doi:10.1007/s 00423-019-01811-z. Cited in: Pubmed; PMID 31468113.

13. Wu WT, Tai FC, Wang PC, et al. Surgical site infection and timing of prophylactic antibiotics for appendectomy. Surg Infect. 2014 Dec;15(6):781-5. eng. Epub 2014/11/18. doi:10.1089/ sur.2013.167. Cited in: Pubmed; PMID 25401521.

14. Koller SE, Bauer KW, Egleston BL, et al. Comparative Effectiveness and Risks of Bowel Preparation Before Elective Colorectal Surgery. Ann Surg. 2018 Apr;267(4):734-42. doi:10.1097/ SLA.0000000000002159. Cited in: Pubmed; PMID 28151800.

15. Fujita $S$, Saito N, Yamada $T$, et al. Randomized, multicenter trial of antibiotic prophylaxis in elective colorectal surgery: single dose vs 3 doses of a second-generation cephalosporin without metronidazole and oral antibiotics. Arch Surg. (Chicago, Ill : 1960). 2007 Jul;142(7):657-61. eng. Epub 2007/07/20. doi:10.1001/ archsurg.142.7.657. Cited in: Pubmed; PMID 17638804.

16. Rollins KE, Javanmard-Emamghissi H, Lobo DN. Impact of mechanical bowel preparation in elective colorectal surgery: A metaanalysis. World J Gastroenterol. 2018 Jan 28;24(4):519-36. doi: 10.3748/wjg.v24.i4.519. Cited in: Pubmed; PMID 29398873.

17. Ljungqvist O, Scott M, Fearon KC. Enhanced Recovery After Surgery: A Review. JAMA surgery. 2017 Mar 1;152(3):292-8. eng. Epub 2017/01/18. doi:10.1001/jamasurg.2016.4952. Cited in: Pubmed; PMID 28097305.

18. Ishibashi K, Kuwabara K, Ishiguro T, et al. Short-term intravenous antimicrobial prophylaxis in combination with preoperative oral antibiotics on surgical site infection and methicillin-resistant Staphylococcus aureus infection in elective colon cancer surgery: results of a prospective randomized trial. Surg Today. 2009;39(12): 1032-9. doi:10.1007/s00595-009-3994-9. Cited in: Pubmed; PMID 19997797.

19. Cuthbertson AM, McLeish AR, Penfold JC, et al. A comparison between single and double dose intravenous Timentin for the prophylaxis of wound infection in elective colorectal surgery. Dis Colon. Rectum. 1991 Feb;34(2):151-5. eng. Epub 1991/02/01. doi: 10.1007/bf02049990. Cited in: Pubmed; PMID 1993412.

20. Mik M, Berut M, Trzcinski R, Dziki L, Buczynski J, Dziki A. Preoperative oral antibiotics reduce infections after colorectal cancer surgery. Langenbecks Arch Surg. 2016;401(8):1153-62. doi: 10.1007/s00423-016-1513-1.

21. Infection JSfS. Perioperative management guideline for prevention of surgical site infection. SHINDAN TO CHIRYO SHA. 2018.

22. Klinger AL, Green H, Monlezun DJ, et al. The Role of Bowel Preparation in Colorectal Surgery: Results of the 2012-2015 ACSNSQIP Data. Ann Surg. 2019 Apr;269(4):671-7. doi:10.1097/ SLA.0000000000002568. Cited in: Pubmed; PMID 29064902.

23. Kaslow SR, Gani F, Alshaikh HN, et al. Clinical outcomes follow- 
ing mechanical plus oral antibiotic bowel preparation versus oral antibiotics alone in patients undergoing colorectal surgery. BJS Open. 2018 Aug;2(4):238-45. doi:10.1002/bjs5.66. Cited in: Pubmed; PMID 30079393.

24. Ministry to Health, Labor and Welfare, Ethical Guidelines for Medical and Health Research Involving Human Subjects [Internet]. 2021 Mar [cited 2021 Mar 3]; Available from: https://www. mhlw.go.jp/stf/seisakunitsuite/bunya/hokabunya/kenkyujigyou/ikenkyu/index.html

25. Hashiguchi Y, Muro K, Saito Y, et al. Japanese Society for Cancer of the Colon and Rectum (JSCCR) guidelines 2019 for the treatment of colorectal cancer. Int J Clin Oncol. 2020 Jan;25(1):1-42. doi:10.1007/s10147-019-01485-z. Cited in: Pubmed; PMID 31203527.

26. Jacobs M, Verdeja JC, Goldstein HS. Minimally invasive colon resection (laparoscopic colectomy). Surg Laparosc Endosc. 1991 Sep;1(3):144-50. eng. Epub 1991/09/01. Cited in: Pubmed; PMID 1688289.

27. Fleshman J, Sargent DJ, Green E, et al. Laparoscopic colectomy for cancer is not inferior to open surgery based on 5-year data from the COST Study Group trial. Ann Surg. 2007 Oct;246(4): 655-62; discussion 662-4. doi:10.1097/SLA.0b013e318155a762.
Cited in: Pubmed; PMID 17893502.

28. Jayne DG, Guillou PJ, Thorpe $\mathrm{H}$, et al. Randomized trial of laparoscopic-assisted resection of colorectal carcinoma: 3-year results of the UK MRC CLASICC Trial Group. J Clin Oncol. 2007 Jul 20;25(21):3061-8. doi:10.1200/JCO.2006.09.7758. Cited in: Pubmed; PMID 17634484.

29. Kitano S, Inomata M, Mizusawa J, et al. Survival outcomes following laparoscopic versus open D3 dissection for stage II or III colon cancer (JCOG0404): a phase 3, randomised controlled trial. Lancet Gastroenterol Hepatol. 2017 Apr;2(4):261-8. eng. Epub 2017/04/14. doi:10.1016/s2468-1253(16)30207-2. Cited in: Pubmed; PMID 28404155.

\section{Supplementary Files}

Supplementary Table 1. Univariate and multivariate analyses to identify risk factors for surgical site infection in a non-mached cohort.

Please find supplementary file(s);

http://dx.doi.org/10.23922/jarc.2021-005

Journal of the Anus, Rectum and Colon is an Open Access journal distributed under the Creative Commons Attribution-NonCommercial-NoDerivatives $4.0 \mathrm{In}$ ternational License. To view the details of this license, please visit (https://creativ ecommons.org/licenses/by-nc-nd/4.0/). 